\title{
Pragmatic measurement of health satisfaction in people with type 2 diabetes mellitus using the Current Health Satisfaction Questionnaire
}

This article was published in the following Dove Press journal:

Patient Related Outcome Measures

26 March 2015

Number of times this article has been viewed

\author{
Shana B Traina' \\ Hilary H Colwell ${ }^{2}$ \\ Ross D Crosby ${ }^{2,3}$ \\ Susan D Mathias \\ 'Janssen Global Services, LLC, \\ Raritan, NJ, ${ }^{2}$ Health Outcomes \\ Solutions, Winter Park, FL, \\ ${ }^{3}$ Neuropsychiatric Research Institute \\ and University of North Dakota \\ School of Medicine and Health \\ Sciences, Fargo, ND, USA
}

Background: The concept of diabetes-related health satisfaction encompasses issues specifically related to living with diabetes (eg, blood glucose, blood pressure levels, body weight). Health satisfaction is more specific than overall health-related quality of life because it considers disease-related factors, and is different from diabetes treatment satisfaction because it addresses issues not specifically related to treatment. Low levels of health satisfaction in people with type 2 diabetes mellitus (T2DM) may negatively affect self-care behaviors and treatment outcomes; however, there are currently no instruments available to assess health satisfaction in this population. This study assessed the measurement properties of a newly constructed, 14-item Current Health Satisfaction Questionnaire (CHES-Q) designed to assess diabetes-related health satisfaction and knowledge of the disease and important laboratory results.

Methods: In-depth interviews were conducted in 23 adults with T2DM to confirm the content and clarity of the CHES-Q. The revised instrument was administered to 1,015 individuals with T2DM, along with supplemental questionnaires, including the Short Form-36. All subjects completed the questionnaires again 3 to 7 days later. CHES-Q test-retest reliability, construct validity, and known-groups validity were evaluated.

Results: In general, respondents found the CHES-Q to be clear and comprehensive. Test-retest reliability was generally acceptable for all items $(\geq 0.70)$, except for three that fell just below the widely accepted cut-point of 0.70 (range 0.63-0.69). Convergent and divergent validity was demonstrated based on hypothesized correlations with the Short Form-36. Known-groups validity was confirmed for most CHES-Q items when respondents were split into groups known to differ clinically by body mass index, disease severity, or glycated hemoglobin.

Conclusion: Health satisfaction is a unique and important concept to consider when developing individualized strategies for managing T2DM because health satisfaction is a key element of patient-centered care. The CHES-Q allows for the pragmatic assessment of many aspects of diabetes-related health satisfaction in a single questionnaire.

Keywords: diabetes, health satisfaction, reliability, validity, Current Health Satisfaction Questionnaire, patient-reported outcomes

\section{Background}

Health satisfaction is a unique concept that is affected by the concerns of people living with a chronic disease. It is more specific than overall health-related quality of life (HRQoL) and different from treatment satisfaction because it considers issues that are not specifically related to treatment. Treatment satisfaction has been defined as a patient's evaluation of the process of taking a specific medication and outcomes associated with that medication, ${ }^{1}$ and has been linked to adherence, compliance, and persistence with medication-taking. ${ }^{2}$ While there is no uniformly accepted definition
Correspondence: Shana B Traina

Cardiovascular and Metabolism, Janssen

Global Services, LLC, 700 Route 202 S,

Raritan, NJ 08869, USA

Tel +l 9089277759

Fax + I 9082533784

Email straina@its.jnj.com 
of health satisfaction, for research purposes, we have defined this concept as the level of contentment one feels regarding various aspects of physical or emotional health, such as body weight, current level of energy, or ability to have social interactions with family and friends.

Poor health satisfaction has been associated with depression, anxiety, stress, reduced energy and physical activity levels, and impaired social functioning. ${ }^{3,4}$ Satisfaction with life and with overall health have been recognized as predictors of long-term treatment outcomes in many chronic conditions, including low back pain, chronic obstructive pulmonary disease, cardiovascular disease, cancer, and diabetes. ${ }^{3,5-9}$ In addition, health satisfaction ratings may affect patients' treatment goals and preferences, ${ }^{10}$ and are therefore important to consider when developing individualized patient-centered approaches for managing chronic diseases that are "respectful of and responsive to individual patient preferences, needs, and values". ${ }^{11}$ For example, a person with diabetes may not value the glucose-lowering effects of a treatment that is associated with weight gain if they are dissatisfied with their current weight and have a desire to lose weight in the near term.

Appropriate measurement of health satisfaction as it relates to type 2 diabetes mellitus (T2DM) should capture concerns that are specifically important to living with this disease, such as blood glucose and blood pressure levels, and body weight. Health satisfaction may directly impact self-care activities that are important for optimizing disease outcomes (eg, controlling dietary intake of calories, carbohydrates, fats, and alcohol; being physically active; adhering to medication; and monitoring blood glucose levels) ${ }^{12}$ by influencing motivation to engage in these health behaviors. For example, a person with T2DM may not be motivated to adhere to medication regimens that are associated with undesirable health impacts such as hypoglycemia or weight gain if they feel dissatisfied with these aspects of their health. By avoiding their medication and its undesirable effects, a person with T2DM might increase their level of health satisfaction in one area (eg, avoiding weight gain) while jeopardizing health satisfaction in another (eg, failing to achieve glucose control). While there are validated instruments, such as the Self-Care Inventory-Revised, ${ }^{12}$ that assess self-care practices in people with T2DM, instruments that assess T2DM disease-specific satisfaction with health are lacking.

A better understanding of health satisfaction at the individual patient level may allow for development of more customized patient-centered management strategies, consistent with current trends in managing chronic disease, as well as current diabetes management guidelines. ${ }^{13}$ Therefore, a measure that evaluates a range of health satisfaction factors specifically known to affect people with T2DM may provide insight into patients' perceptions about their health, which in turn may lead to more targeted individualized treatment and self-management plans. For instance, those with low levels of satisfaction with body weight may benefit from antihyperglycemic treatments that also offer the benefit of weight loss.

As part of the planning for Phase III clinical trials of canagliflozin, patient-reported instruments were selected to explore endpoints that would account for the central role of patientspecific factors in determining T2DM outcomes. During this process, measurement of the concept of health satisfaction was identified as a gap, as there were no known measures available to readily capture this concept in a clinical trial setting. To address the imminent need for a single disease-specific health satisfaction instrument in T2DM that could be utilized in the clinical trials of canagliflozin, the Current Health Satisfaction Questionnaire (CHES-Q) was developed using a pragmatic, minimalist approach. Here we describe the development of the CHES-Q and briefly report the results from cognitive interviews used to confirm the relevance of its content. We also present the results of a pilot study that assessed its measurement properties, including test-retest reliability, convergent/ divergent validity, and known-groups validity.

\section{Materials and methods Development and description of the CHES-Q}

A team of experts who are engaged in interdisciplinary patientreported outcome and T2DM research developed a draft CHES-Q for use in a clinical trial setting. This draft questionnaire (Table 1) was developed based on input from health care professionals and patients (obtained as part of patient interviews conducted at the completion of a Phase II clinical study in individuals with T2DM), ${ }^{14}$ as well as from findings from the published literature and qualitative and quantitative research involving people with and without T2DM and their attitudes toward behaviors such as weight loss and physical activity.

The CHES-Q was designed to evaluate factors influencing patients' motivation to change behaviors (eg, diet and exercise habits) and measure knowledge of and satisfaction with health. Items in the CHES-Q were intended to represent a breadth of health satisfaction and knowledge concepts that may be important to people with T2DM. It was important not only to capture satisfaction with relevant aspects of health, such as body weight and blood glucose levels, but also to assess knowledge of things like current blood glucose levels for interpretation of levels of 
Table I CHES-Q, English version*. Please circle one number for each question to indicate how much you agree or disagree with each of the following statements about your current health and knowledge of diabetes.

\begin{tabular}{|c|c|c|c|c|c|c|c|}
\hline & $\begin{array}{l}\text { Strongly } \\
\text { disagree }\end{array}$ & Disagree & $\begin{array}{l}\text { Somewhat } \\
\text { disagree }\end{array}$ & $\begin{array}{l}\text { Neither agree } \\
\text { nor disagree }\end{array}$ & $\begin{array}{l}\text { Somewhat } \\
\text { agree }\end{array}$ & Agree & $\begin{array}{l}\text { Strongly } \\
\text { agree }\end{array}$ \\
\hline $\begin{array}{l}\text { I. I am satisfied with my current } \\
\text { body weight. }\end{array}$ & I & 2 & 3 & 4 & 5 & 6 & 7 \\
\hline $\begin{array}{l}\text { 2. I am satisfied with my current } \\
\text { level of energy. }\end{array}$ & I & 2 & 3 & 4 & 5 & 6 & 7 \\
\hline $\begin{array}{l}\text { 3. I am satisfied with my current appetite } \\
\text { (my overall desire to eat). }\end{array}$ & I & 2 & 3 & 4 & 5 & 6 & 7 \\
\hline $\begin{array}{l}\text { 4. I am satisfied with my current } \\
\text { ability to sleep through the night. }\end{array}$ & I & 2 & 3 & 4 & 5 & 6 & 7 \\
\hline $\begin{array}{l}\text { 5. I am satisfied with my current } \\
\text { ability to do physical activities } \\
\text { such as walk or climb stairs. }\end{array}$ & I & 2 & 3 & 4 & 5 & 6 & 7 \\
\hline $\begin{array}{l}\text { 6. I am satisfied with my current } \\
\text { ability to have social interactions } \\
\text { with family and friends. }\end{array}$ & I & 2 & 3 & 4 & 5 & 6 & 7 \\
\hline $\begin{array}{l}\text { 7. I am satisfied with my current } \\
\text { attitude toward diabetes. }\end{array}$ & I & 2 & 3 & 4 & 5 & 6 & 7 \\
\hline $\begin{array}{l}\text { 8. I am satisfied with my current } \\
\text { mood. }\end{array}$ & I & 2 & 3 & 4 & 5 & 6 & 7 \\
\hline $\begin{array}{l}\text { 9. I know my current blood sugar } \\
\text { levels. }\end{array}$ & I & 2 & 3 & 4 & 5 & 6 & 7 \\
\hline $\begin{array}{l}\text { 10. I am satisfied with my current } \\
\text { blood sugar levels. }\end{array}$ & I & 2 & 3 & 4 & 5 & 6 & 7 \\
\hline $\begin{array}{l}\text { II. I know my current blood } \\
\text { pressure. }\end{array}$ & I & 2 & 3 & 4 & 5 & 6 & 7 \\
\hline $\begin{array}{l}\text { 12. I am satisfied with my current } \\
\text { blood pressure. }\end{array}$ & I & 2 & 3 & 4 & 5 & 6 & 7 \\
\hline $\begin{array}{l}\text { 13. Overall, I am satisfied with } \\
\text { my current health. }\end{array}$ & I & 2 & 3 & 4 & 5 & 6 & 7 \\
\hline $\begin{array}{l}\text { 14. My current level of knowledge } \\
\text { about diabetes is ... }\end{array}$ & $\begin{array}{l}\text { I } \\
\text { Not at all } \\
\text { knowledgeable }\end{array}$ & $\begin{array}{l}2 \\
\text { Sor } \\
\text { knc }\end{array}$ & $\begin{array}{l}\text { what } \\
\text { ledgeable }\end{array}$ & $\begin{array}{l}3 \\
\text { Knowledgeable }\end{array}$ & $\begin{array}{l}4 \\
\text { Very } \\
\text { knowledgeable }\end{array}$ & $\begin{array}{l}5 \\
E \\
k\end{array}$ & $\begin{array}{l}\text { remely } \\
\text { wledgeable }\end{array}$ \\
\hline
\end{tabular}

Notes: *Use of CHES-Q requires permission by the instrument owner, Janssen Research and Development, LLC.

Abbreviation: CHES-Q, Current Health Satisfaction Questionnaire.

satisfaction. For example, if a person with T2DM reports they do not know their current blood sugar levels, their response to level of satisfaction with this parameter is questionable and therefore might be excluded from analyses of aggregate data.

Based on the output from this work, 14 items were drafted for inclusion in the CHES-Q, with eleven items focusing on satisfaction with weight, energy, appetite, sleep, physical functioning, social interactions, attitude, mood, blood sugar levels, blood pressure, and current health, and three items assessing knowledge of current blood sugar levels, blood pressure levels, and diabetes. It was important to capture these knowledge topics, as they have been linked to health satisfaction. ${ }^{15,16}$ If a person does not know their clinical variables (eg, blood sugar levels, blood pressure, body weight) and the meaning of these variables, assessment of their level of satisfaction may be uninterpretable.
Response options for satisfaction items were rated on a seven-point scale, ranging from "strongly disagree" to "strongly agree", and responses for knowledge items were rated on a five-point scale, ranging from "not at all knowledgeable" to "extremely knowledgeable". Higher scores indicate higher satisfaction or knowledge. Each item measures a distinct concept and is scored individually. For this pilot analysis, items 10 and 12, which ask about satisfaction with blood sugar levels and blood pressure, respectively, were only scored if the respondent indicated that they "somewhat agree", "agree", or "strongly agree" with the statements "I know my current blood sugar levels" (item 9) and "I know my current blood pressure" (item 11). However, the instrument allows for flexibility in scoring (eg, items could be scored more conservatively using only "agree" or "strongly agree" responses to items 9 and 11). 


\section{Study design}

This study was conducted in two stages. First, in-depth inperson and telephone interviews were undertaken to confirm that the content of the draft CHES-Q was appropriate, clear, and relevant, with no missing items. Once completed, other individuals with T2DM completed an online questionnaire containing the CHES-Q and collateral measures. These data were used to evaluate the measurement properties of the draft questionnaire. Both stages of the study received approval from the Copernicus Group Institutional Review Board (Durham, NC, USA; http://www.cgirb.com).

Participants were recruited from Harris Interactive's proprietary Chronic Illness Panel, eRewards, or Toluna databases. ${ }^{17}$ To be eligible for inclusion in either the qualitative or quantitative component of the study, participants (via self-report) were required to be aged $\geq 18$ years, diagnosed with T2DM and taking a T2DM medication, and have a body mass index (BMI) of 20 to $\leq 45 \mathrm{~kg} / \mathrm{m}^{2}$ (based on self-reported height and weight). If diagnosed with anxiety or depression, the inclusion criteria required no change in medications for anxiety or depression in the past 3 months. Participants were excluded if they had type 1 diabetes, a major depressive disorder, a personality disorder, or an eating disorder in the past 3 months; were currently taking antipsychotics; were currently pregnant or had been pregnant in the previous 12 months; or had previous or scheduled gastric bypass surgery, lap band, or liposuction. These inclusion and exclusion criteria were designed to match the criteria used in the Phase III clinical trial program for canagliflozin.

\section{Qualitative research (stage I)}

Potential respondents with T2DM were contacted by telephone and screened for eligibility. Written informed consent was obtained from each eligible respondent, and an interview was scheduled. In-person cognitive interviews were conducted initially, followed by telephone interviews. Respondents were recruited in blocks of six to eight participants, and data were reviewed after each block to determine whether new concepts were being discussed and additional interviews were needed. All interviews were conducted using a semi-structured interview guide, which included questions about the respondent's general understanding of the items/instructions, and relevance of items and time frame. Interviews lasted 50 to 60 minutes and were transcribed and analyzed.

\section{Quantitative research (stage 2)}

Potential respondents were emailed a link to an online screener. If eligible, the respondent provided consent and completed an online questionnaire including the Short Form (SF)-36, version 2-acute ${ }^{18}$ and original items relevant to the treatment and management of T2DM (eg, whether they know their blood pressure or glycated hemoglobin $\left.\left[\mathrm{HbA}_{1 c}\right]\right)$.

To assess test-retest reliability, all respondents were asked to complete the CHES-Q and items about change in health status 3 to 7 days after completing the first questionnaire. This interval was selected to be short enough not to anticipate any clinical changes that might influence responses to the CHES-Q items. All respondents were asked to complete another follow-up questionnaire 12 months later.

\section{Statistical methods}

Demographic and self-reported clinical characteristics (eg, disease severity and BMI [calculated using self-reported height and weight]) were examined. To evaluate whether responses to CHES-Q items differed by patient demographic characteristics, responses were compared using independent samples $t$-tests (sex, race, marital status, education) or oneway analysis of variance (income). Pearson correlations were computed between CHES-Q items and age.

Exploratory factor analysis and confirmatory factor analysis were undertaken to determine the structure and scoring of the CHES-Q; factors with eigenvalues $>1.0$ were retained. In addition, the percentage of responses at the lowest value (floor) and at the highest value (ceiling) was calculated for each item. Floor and ceiling effects were determined to be present if $\geq 15 \%$ of respondents chose either the lowest or highest response..$^{19,20}$

Analysis of test-retest reliability (ie, the extent to which a measure yields consistent scores over a short period of time, assuming there is no underlying change in health status) was restricted to subjects who reported no changes in health (eg, had not been ill, medication had not changed, had not lost or gained $\geq 3 \mathrm{lb}$ ) on the follow-up questionnaire. Results were evaluated using the intraclass correlation coefficient. An intraclass correlation coefficient $\geq 0.70$ for each item was considered to reflect acceptable test-retest reliability. ${ }^{21}$ A paired $t$-test was calculated to assess whether there were shifts in mean response over this time frame.

Convergent validity is demonstrated when scales or items thought to measure the same construct have high correlation coefficients, while divergent validity is demonstrated when scales or items thought to measure different constructs have low correlation coefficients. Because there are similar concepts captured by both the SF-36 and CHES-Q, it was hypothesized that there would be moderate to high levels of correlations between several SF-36 scales and 
CHES-Q items. For example, it was hypothesized that the CHES-Q item about physical activities would be moderately to highly correlated with the physical component summary score of the SF-36 (convergent validity). Convergent and divergent validity were evaluated by calculating Pearson correlation coefficients for CHES-Q items with items from the SF-36. ${ }^{18}$ Importantly, comparisons were made between the magnitude of the association of the CHES-Q with BMI and the association of SF-36 scores with BMI because satisfaction with weight is a driver of behavior and HRQoL, and SF-36 scores are sensitive to BMI categories. ${ }^{22-26}$

Known-groups validity analyses were conducted to determine whether the CHES-Q was better able to distinguish between patients known to differ based on clinical factors (BMI [based on self-reported height/weight], disease severity, and $\mathrm{HbA}_{1 \mathrm{c}}$ level). Respondents were categorized based on their self-reported BMI category (available choices were $<25$, 25-29.9, 30-39.9, and $\left.\geq 40 \mathrm{~kg} / \mathrm{m}^{2}\right),{ }^{27}$ self-reported most recent $\mathrm{HbA}_{1 \mathrm{c}}$ level (available choices were $\leq 6 \%, 6.1 \%-6.5 \%$, $6.6 \%-7.0 \%, 7.1 \%-7.5 \%, 7.6 \%-8.0 \%$, and $>8 \%$ ), and selfreported diabetes severity (available choices were "mild", "moderate", and "severe"). It was hypothesized that those with lower BMI, $\mathrm{HbA}_{1 \mathrm{c}}$ levels, and disease severity ratings would report greater satisfaction with health than those with higher $\mathrm{BMI}, \mathrm{HbA}_{1 \mathrm{c}}$ levels, and disease severity ratings.

The minimal clinical important change (MCIC) was estimated using three distribution-based approaches: 1 standard error of measurement, 0.5 standardized effect size, and 0.5 responsiveness statistic. ${ }^{28,29}$ To examine known groups, respondents were categorized based on their responses to the general health item from the SF-36 ("In general, would you say your health is excellent, very good, good, fair, or poor"). The transition health item from the SF-36 ("Compared to 1 week ago, how would you rate your health in general now [much better, somewhat better, about the same, somewhat worse, much worse]?") was used to exclude any respondents with health changes during examination of test-retest reliability.

\section{Results \\ Qualitative research results}

During the first stage, 23 interviews were conducted (16 in person and seven by telephone). Approximately half of the subjects were female (52\%), aged 18 to 45 years $(52 \%)$, and Caucasian (52\%). Mean BMI was $27.9 \mathrm{~kg} / \mathrm{m}^{2}$ (n=19) among subjects who reported height and weight.

In general, the 23 individuals who completed qualitative cognitive interviews found the instructions, items, and response options in the CHES-Q to be brief yet comprehensive, clear, and easy to complete. Some comments were provided, but they were not substantive enough to warrant modifications to the questionnaire. For instance, some respondents preferred the use of five-point response options (rather than seven options). Respondents generally endorsed the CHES-Q as containing relevant concepts related to their T2DM. However, there was some variation in the perceived relevance of items related to physical activity (item 5), social interactions (item 6), mood (item 8), and blood pressure (items 11 and 12). In general, respondents who reported limitations in these areas were more likely to consider them relevant to their T2DM-related health satisfaction than those with no difficulties in these areas. The items were therefore retained as relevant to the subset of people living with T2DM who experience difficulties with these aspects of health.

\section{Quantitative research results}

During the second stage of the study, 1,015 respondents completed the first set of online questionnaires. Clinical and demographic characteristics for these 1,015 respondents are summarized in Table 2. On average, respondents had been diagnosed with diabetes roughly 12 years ago, mean age at diagnosis was 51 years, and most were taking an oral antihyperglycemic agent. The mean age of the respondents was $63 \pm 11$ years. The majority of the sample was male, Caucasian, married, obese or extremely obese (mean BMI $32.1 \mathrm{~kg} / \mathrm{m}^{2}$ ), and had an annual income of $\leq \$ 100,000$. Forty-six percent had at least a college degree. The second (retest) set of online questionnaires was completed by 529 respondents who reported an unchanged health status, and these responses were included in the test-retest analysis.

Mean responses were significantly higher on several CHES-Q items for males (items 1, 2, 3, and 5 [see Table 1 for item content]; $P<0.004)$ and those with higher income (items $2,4,5,6$, and $8 ; P<0.008$ ). Few differences were found by race, marital status, or education. Age was significantly correlated with all CHES-Q items except physical activities, knowledge of diabetes, and satisfaction with current blood sugar levels. Correlations ranged from -0.125 (satisfied with current blood pressure) to 0.236 (satisfied with current mood).

There were statistically significant differences $(P<0.05)$ between those included, in the test-retest analysis group and those who were not included, in terms of time since diabetes diagnosis, types of diabetes medications used, sex, age, ethnicity, marital status, and income. The retest group was 
Table 2 Clinical and demographic characteristics of the online questionnaire population

\begin{tabular}{|c|c|}
\hline Characteristics $(\mathrm{N}=1,015)$ & Value \\
\hline Age at diabetes diagnosis, years (mean $\pm \mathrm{SD}$ ) & $51 \pm 12$ \\
\hline Time since diabetes diagnosis, years (mean \pm SD) & $12 \pm 9$ \\
\hline \multicolumn{2}{|l|}{ Antihyperglycemic treatment (\%) } \\
\hline Oral only & 65 \\
\hline Oral + insulin & 18 \\
\hline Injectable (non-insulin) & 6 \\
\hline Insulin only & 11 \\
\hline \multicolumn{2}{|l|}{ Sex $(\%)$} \\
\hline Male & 60 \\
\hline Female & 40 \\
\hline Age, years (mean $\pm S D$ ) & $63 \pm 11$ \\
\hline \multicolumn{2}{|l|}{ Race/ethnicity (\%) } \\
\hline Caucasian (non-Hispanic) & 84 \\
\hline African American & 4 \\
\hline Hispanic & 7 \\
\hline Other & 3 \\
\hline Declined to answer & 2 \\
\hline \multicolumn{2}{|l|}{ Marital status (\%) } \\
\hline Never married & 9 \\
\hline Married/living with partner & 68 \\
\hline Divorced/widow/separated & 22 \\
\hline Declined to answer & I \\
\hline \multicolumn{2}{|l|}{ Education (\%) } \\
\hline$<$ High school & 16 \\
\hline Some college/associate degree & 38 \\
\hline College degree & 17 \\
\hline Some graduate school & 10 \\
\hline Graduate degree & 19 \\
\hline \multicolumn{2}{|l|}{ Income (\%) } \\
\hline$<\$ 25,000$ & 13 \\
\hline$\$ 25,000-\$ 49,999$ & 26 \\
\hline$\$ 50,000-\$ 99,999$ & 31 \\
\hline$>\$ 100,000$ & 16 \\
\hline Declined to answer & 14 \\
\hline \multicolumn{2}{|l|}{$\mathrm{BMI}, \mathrm{kg} / \mathrm{m}^{2}(\%)$} \\
\hline Normal $(<25)$ & 10 \\
\hline Overweight (25-29.9) & 31 \\
\hline Obese $(30-39.9)$ & 49 \\
\hline Extremely obese $(\geq 40)$ & 10 \\
\hline
\end{tabular}

Abbreviations: SD, standard deviation; BMI, body mass index.

slightly older and reported an older age at the time of their diabetes diagnosis. The retest group included a greater percentage of males, Caucasians, married individuals, and people with an annual income $>\$ 75,000$, as well as those who took oral medications only.

\section{Factor analysis}

Exploratory factor analysis of CHES-Q items identified three factors with eigenvalues $>1.0$. However, one CHES-Q item (item 4 ) failed to load $>0.40$ on any factor. Confirmatory factor analysis testing of this factor structure failed to provide good fit for models including (root mean square error of approximation $=0.104$, comparative fit index $=0.876$, Tucker-Lewis index $=0.844$, standardized root mean square residual $=0.068$ ) or excluding (root mean square error of approximation $=0.113$, comparative fit index $=0.873$, Tucker-Lewis index $=0.835$, standardized root mean square residual $=0.069$ ) this item. These findings provided support for the reporting of separate CHES-Q items.

\section{Floor and ceiling effects}

The percentage of responses at the lowest value (floor) ranged from $2 \%$ to $25 \%$ for the first administration of the questionnaire (items 1,2 , and 5 exceeded the cutoff of $\geq 15 \%$ ) and from $2 \%$ to $26 \%$ for the second administration (the same three items exceeded the cutoff), while the percentage at the highest value (ceiling) ranged from $3.4 \%$ to $36.1 \%$ for the first administration (items 6, 7, 8, 9, 10, 11, and 12 exceeded the cutoff of $\geq 15 \%$ ) and $2.9 \%$ to $40.2 \%$ (the same seven items exceeded the cutoff) for the second administration.

\section{Test-retest reliability}

Test-retest reliability (mean interval $4.7 \pm 1.7$ days) was acceptable for the majority of items, with intraclass correlation coefficients ranging from 0.63 to 0.83 . All items had reliability coefficients above 0.70 except for appetite (0.67), social interactions (0.63), and mood (0.69). It was not surprising that appetite and mood had lower reliability coefficients, as these aspects can change on a daily basis and even throughout the day. Body weight, appetite, and attitude showed statistically significant shifts $(P<0.05)$ in means over time. Body weight and appetite increased, and attitude decreased over time, but all changes were $<1.0$ point (which is less than one categorical change) over the 3-day to 7-day retest period (see MCIC results section).

\section{Convergent/divergent validity}

Table 3 displays correlations between CHES-Q items and SF-36 scale and component scores. Pre-specified expected relationships were observed between CHES-Q items and SF-36 component scores. The physical component summary score was most highly correlated $(P<0.001)$ with satisfaction regarding ability to do physical activities $(r=0.70)$, followed by overall satisfaction with health $(r=0.55)$, satisfaction with current level of energy $(r=0.50)$, and satisfaction with ability to have social interactions with family and friends $(r=0.32)$. The mental component summary score was most highly correlated $(P<0.001)$ with satisfaction with $\operatorname{mood}(r=0.66)$, followed by satisfaction with ability to have social interactions with family and friends $(r=0.53)$, satisfaction with attitude toward diabetes 
Table 3 Convergent/divergent validity-correlations between CHES-Q items and SF-36 scales

\begin{tabular}{|c|c|c|c|c|c|c|c|c|c|c|}
\hline Item from CHES-Q & PF & $\mathbf{R P}$ & BP & GH & VT & SF & $\mathbf{R E}$ & MH & PCS & MCS \\
\hline QI: Satisfaction with current body weight & 0.13 & 0.14 & 0.18 & 0.22 & 0.26 & 0.08 & $0.04^{*}$ & 0.18 & 0.18 & 0.12 \\
\hline Q2: Satisfaction with current level of energy & 0.44 & 0.46 & 0.42 & 0.56 & 0.67 & 0.36 & 0.31 & 0.40 & 0.50 & 0.38 \\
\hline $\begin{array}{l}\text { Q3: Satisfaction with current appetite (overall desire } \\
\text { to eat) }\end{array}$ & 0.19 & 0.18 & 0.21 & 0.32 & 0.33 & 0.18 & 0.17 & 0.29 & 0.20 & 0.25 \\
\hline $\begin{array}{l}\text { Q4: Satisfaction with current ability to sleep through } \\
\text { the night }\end{array}$ & 0.19 & 0.25 & 0.29 & 0.32 & 0.38 & 0.26 & 0.23 & 0.35 & 0.23 & 0.33 \\
\hline $\begin{array}{l}\text { Q5: Satisfaction with current ability to do physical } \\
\text { activities such as walk or climb stairs }\end{array}$ & 0.69 & 0.58 & 0.54 & 0.59 & 0.58 & 0.41 & 0.35 & 0.32 & 0.70 & 0.26 \\
\hline $\begin{array}{l}\text { Q6: Satisfaction with current ability to have social } \\
\text { interactions with family and friends }\end{array}$ & 0.34 & 0.40 & 0.33 & 0.41 & 0.49 & 0.55 & 0.41 & 0.51 & 0.32 & 0.53 \\
\hline Q7: Satisfaction with current attitude toward diabetes & 0.15 & 0.20 & 0.19 & 0.35 & 0.40 & 0.28 & 0.24 & 0.44 & 0.15 & 0.41 \\
\hline Q8: Satisfaction with current mood & 0.24 & 0.35 & 0.28 & 0.44 & 0.57 & 0.47 & 0.41 & 0.70 & 0.21 & 0.66 \\
\hline Q9: Knowledge of current blood sugar levels & 0.02 & 0.08 & 0.08 & 0.14 & 0.17 & 0.12 & 0.10 & 0.22 & $0.04 *$ & 0.21 \\
\hline Q10: Satisfaction with current blood sugar levels & $0.04 *$ & 0.09 & 0.07 & 0.27 & 0.28 & $0.07^{*}$ & 0.10 & 0.25 & 0.08 & 0.22 \\
\hline QII: Knowledge of current blood pressure & $0.03^{*}$ & 0.10 & 0.10 & 0.21 & 0.20 & 0.15 & 0.15 & 0.26 & $0.05 *$ & 0.25 \\
\hline Q12: Satisfaction with current blood pressure & 0.10 & 0.13 & $0.06 *$ & 0.14 & 0.14 & 0.12 & $0.04^{*}$ & 0.15 & 0.10 & 0.11 \\
\hline QI3: Overall satisfaction with current health & 0.46 & 0.49 & 0.44 & 0.73 & 0.60 & 0.41 & 0.31 & 0.46 & 0.55 & 0.39 \\
\hline Q14: Current level of knowledge about diabetes & $0.01 *$ & $0.03^{*}$ & $-0.00 *$ & 0.08 & 0.13 & $0.05 *$ & $0.03 *$ & 0.11 & $0.01 *$ & 0.11 \\
\hline
\end{tabular}

Notes: Bold font indicates moderate to high $(\geq 0.30)$ correlation while regular font indicates low $(<0.30)$ correlation between SF-36 and CHES-Q. $*$ Not significantly correlated $(P>0.05)$.

Abbreviations: CHES-Q, Current Health Satisfaction Questionnaire; SF-36, Short Form-36; PF, physical functioning; RP, role-physical; BP, bodily pain; GH, general health; VT, vitality; SF, social functioning; RE, role-emotional; MH, mental health; PCS, physical component summary score; MCS, mental component summary score.

$(r=0.41)$, overall satisfaction with current health $(r=0.39)$, satisfaction with energy level $(r=0.38)$, and satisfaction with ability to sleep through the night $(r=0.33)$.

For SF-36 scale scores, satisfaction with energy level was more highly correlated with the vitality score $(r=0.67$, $P<0.001$ ) than with any other SF-36 score (range $0.31-0.56$ ). Satisfaction with social interactions was more highly correlated with the social functioning score $(r=0.55, P<0.001)$ than with any other SF-36 scale score (range $0.32-0.53$ ). In general, low correlations were reported between CHES-Q items that measured different concepts from the SF-36. For example, low correlations (range 0.04-0.15) were reported between satisfaction with blood pressure and SF-36 scale and component scores.

Pearson correlation coefficients between BMI and CHES$\mathrm{Q}$ items ranged from -0.53 to -0.03 (data not shown). Correlations were statistically significant (two-tailed $P<0.01$ ) and in the expected direction for all satisfaction-related questions. As expected, significant correlations were not observed between BMI and knowledge of current blood sugar levels, blood pressure, and diabetes, since knowledge alone is not hypothesized to be sufficient to impact BMI, and BMI has not been shown to be predictive of knowledge.

\section{Known-groups validity}

Known-groups validity analyses were conducted based on BMI, disease severity levels, and $\mathrm{HbA}_{1 \mathrm{c}}$. Based on BMI categories (Table 4), there were significant differences
$(P<0.05)$ among groups on all items except knowledge of current blood sugar values $(P=0.213)$ and knowledge of diabetes $(P=0.379)$. For all items, there were significant differences between the $\geq 40$ and $<25 \mathrm{~kg} / \mathrm{m}^{2}$ BMI groups.

Based on disease severity categories, statistically significant differences $(P<0.05)$ were reported between groups on all items except knowledge of current blood sugar levels ( $P=0.236)$, satisfaction with blood pressure $(P=0.468)$, and knowledge of diabetes $(P=0.469$; Table 5$)$. There were significant differences between the "mild" and "severe" groups for all items. In general, those with less severe disease ratings reported higher levels of satisfaction.

When comparing $\mathrm{HbA}_{1 \mathrm{c}}$ categories, there were significant differences $(P<0.05)$ among groups on all items, except satisfaction with blood pressure (Table 4). There were statistically significant differences $(P<0.05)$ between the $\leq 6.0 \%$ and the $>8 \%$ groups and between the $\leq 6.0 \%$ and the $7.6 \%$ to $8.0 \%$ groups for all items except current knowledge of diabetes. In general, those with lower $\mathrm{HbA}_{1 \mathrm{c}}$ categories reported higher levels of satisfaction. However, for most items, the $\mathrm{HbA}_{1 \mathrm{c}}$ $>8 \%$ group reported higher levels of satisfaction than the $7.6 \%$ to $8.0 \%$ group.

\section{Minimal clinical important change}

Individual estimated MCICs ranged from 0.5 to 1 point, depending on the item and approach (standard error of measurement, standardized effect size, or responsiveness statistic; Table 6). Therefore, the MCIC should be approximately 1 point 
Table 4 Mean scores for CHES-Q items* by $\mathrm{BMI}$ and $\mathrm{HbA}_{\mathrm{Ic}}$ categories

\begin{tabular}{|c|c|c|c|c|c|c|}
\hline Item & $\begin{array}{l}\text { BMI }\left(\mathrm{kg} / \mathrm{m}^{2}\right) \text { categories } \\
(\mathrm{N}=1,015)\end{array}$ & Mean \pm SD $^{\#}$ & $P$-value & $\begin{array}{l}\text { HbA } A_{I c} \text { categories } \\
(n=82 I)\end{array}$ & Mean \pm SD $^{\#}$ & $P$-value \\
\hline $\begin{array}{l}\text { QI: Satisfied with current body } \\
\text { weight }\end{array}$ & $\begin{array}{l}<25(n=82) \\
25-29.9(n=317) \\
30-39.9(n=498) \\
\geq 40(n=102)\end{array}$ & $\begin{array}{l}5.1 \pm 1.7 \\
3.3 \pm 1.6 \\
2.2 \pm 1.2 \\
1.6 \pm 0.97\end{array}$ & $<0.001$ & $\begin{array}{l}\leq 6.0 \%(n=130) \\
6.1 \%-6.5 \%(n=211) \\
6.6 \%-7.0 \%(n=218) \\
7.1 \%-7.5 \%(n=147) \\
7.6 \%-8.0 \%(n=51) \\
>8.0 \%(n=64)\end{array}$ & $\begin{array}{l}2.9 \pm 1.9 \\
2.8 \pm 1.7 \\
2.8 \pm 1.7 \\
2.6 \pm 1.6 \\
1.8 \pm 0.97 \\
2.3 \pm 1.3\end{array}$ & 0.001 \\
\hline $\begin{array}{l}\text { Q2: Satisfied with current level } \\
\text { of energy }\end{array}$ & $\begin{array}{l}<25 \\
25-29.9 \\
30-39.9 \\
\geq 40\end{array}$ & $\begin{array}{l}4.5 \pm 1.8 \\
3.8 \pm 1.7 \\
3.0 \pm 1.6 \\
2.3 \pm 1.5\end{array}$ & $<0.001$ & $\begin{array}{l}\leq 6.0 \% \\
6.1 \%-6.5 \% \\
6.6 \%-7.0 \% \\
7.1 \%-7.5 \% \\
7.6 \%-8.0 \% \\
>8.0 \%\end{array}$ & $\begin{array}{l}3.5 \pm 1.9 \\
3.4 \pm 1.8 \\
3.6 \pm 1.7 \\
3.2 \pm 1.7 \\
2.5 \pm 1.6 \\
2.6 \pm 1.5\end{array}$ & $<0.001$ \\
\hline Q3: Satisfied with current appetite & $\begin{array}{l}<25 \\
25-29.9 \\
30-39.9 \\
\geq 40\end{array}$ & $\begin{array}{l}5.3 \pm 1.4 \\
4.8 \pm 1.6 \\
3.9 \pm 1.7 \\
3.7 \pm 1.8\end{array}$ & $<0.001$ & $\begin{array}{l}\leq 6.0 \% \\
6.1 \%-6.5 \% \\
6.6 \%-7.0 \% \\
7.1 \%-7.5 \% \\
7.6 \%-8.0 \% \\
>8.0 \%\end{array}$ & $\begin{array}{l}4.5 \pm 1.8 \\
4.4 \pm 1.7 \\
4.4 \pm 1.6 \\
4.2 \pm 1.7 \\
3.4 \pm 1.9 \\
3.6 \pm 2.0\end{array}$ & $<0.001$ \\
\hline Q4: Satisfied with ability to sleep & $\begin{array}{l}<25 \\
25-29.9 \\
30-39.9 \\
\geq 40\end{array}$ & $\begin{array}{l}4.7 \pm 1.8 \\
4.5 \pm 1.8 \\
4.0 \pm 1.9 \\
3.9 \pm 2.1\end{array}$ & $<0.001$ & $\begin{array}{l}\leq 6.0 \% \\
6.1 \%-6.5 \% \\
6.6 \%-7.0 \% \\
7.1 \%-7.5 \% \\
7.6 \%-8.0 \% \\
>8.0 \%\end{array}$ & $\begin{array}{l}4.5 \pm 1.9 \\
4.4 \pm 1.8 \\
4.2 \pm 1.8 \\
4.1 \pm 1.9 \\
3.5 \pm 1.9 \\
3.7 \pm 2.2\end{array}$ & 0.007 \\
\hline $\begin{array}{l}\text { Q5: Satisfied with ability } \\
\text { to do physical activities }\end{array}$ & $\begin{array}{l}<25 \\
25-29.9 \\
30-39.9 \\
\geq 40\end{array}$ & $\begin{array}{l}5.0 \pm 1.9 \\
4.6 \pm 1.9 \\
3.5 \pm 1.9 \\
2.9 \pm 1.7\end{array}$ & $<0.001$ & $\begin{array}{l}\leq 6.0 \% \\
6.1 \%-6.5 \% \\
6.6 \%-7.0 \% \\
7.1 \%-7.5 \% \\
7.6 \%-8.0 \% \\
>8.0 \%\end{array}$ & $\begin{array}{l}4.0 \pm 2.2 \\
4.0 \pm 2.0 \\
4.3 \pm 1.9 \\
3.8 \pm 1.9 \\
3.0 \pm 1.7 \\
3.5 \pm 1.9\end{array}$ & $<0.001$ \\
\hline $\begin{array}{l}\text { Q6: Satisfied with ability to have } \\
\text { social interactions }\end{array}$ & $\begin{array}{l}<25 \\
25-29.9 \\
30-39.9 \\
\geq 40\end{array}$ & $\begin{array}{l}6.0 \pm 1.2 \\
5.7 \pm 1.4 \\
5.5 \pm 1.5 \\
5.1 \pm 1.7\end{array}$ & $<0.001$ & $\begin{array}{l}\leq 6.0 \% \\
6.1 \%-6.5 \% \\
6.6 \%-7.0 \% \\
7.1 \%-7.5 \% \\
7.6 \%-8.0 \% \\
>8.0 \%\end{array}$ & $\begin{array}{l}5.6 \pm 1.6 \\
5.8 \pm 1.3 \\
5.8 \pm 1.2 \\
5.5 \pm 1.4 \\
5.1 \pm 1.7 \\
5.1 \pm 1.8\end{array}$ & 0.004 \\
\hline $\begin{array}{l}\text { Q7: Satisfied with current } \\
\text { attitudes toward diabetes }\end{array}$ & $\begin{array}{l}<25 \\
25-29.9 \\
30-39.9 \\
\geq 40\end{array}$ & $\begin{array}{l}5.9 \pm 1 . I \\
5.6 \pm I .3 \\
5.1 \pm I .5 \\
4.8 \pm I .6\end{array}$ & $<0.001$ & $\begin{array}{l}\leq 6.0 \% \\
6.1 \%-6.5 \% \\
6.6 \%-7.0 \% \\
7.1 \%-7.5 \% \\
7.6 \%-8.0 \% \\
>8.0 \%\end{array}$ & $\begin{array}{l}5.8 \pm 1.3 \\
5.6 \pm 1.3 \\
5.5 \pm 1.3 \\
5.0 \pm 1.4 \\
4.3 \pm 1.8 \\
4.6 \pm 1.7\end{array}$ & $<0.001$ \\
\hline Q8: Satisfied with current mood & $\begin{array}{l}<25 \\
25-29.9 \\
30-39.9 \\
\geq 40\end{array}$ & $\begin{array}{l}5.7 \pm 1.3 \\
5.5 \pm 1.4 \\
5.2 \pm 1.5 \\
5.0 \pm 1.7\end{array}$ & $<0.001$ & $\begin{array}{l}\leq 6.0 \% \\
6.1 \%-6.5 \% \\
6.6 \%-7.0 \% \\
7.1 \%-7.5 \% \\
7.6 \%-8.0 \% \\
>8.0 \%\end{array}$ & $\begin{array}{l}5.4 \pm 1.5 \\
5.5 \pm 1.3 \\
5.6 \pm 1.2 \\
5.2 \pm 1.4 \\
4.4 \pm 2.0 \\
4.6 \pm 2.0\end{array}$ & $<0.001$ \\
\hline $\begin{array}{l}\text { Q9: I know my current blood } \\
\text { sugar levels }\end{array}$ & $\begin{array}{l}<25 \\
25-29.9 \\
30-39.9 \\
\geq 40\end{array}$ & $\begin{array}{l}5.8 \pm 1.5 \\
5.8 \pm 1.4 \\
5.6 \pm 1.6 \\
5.6 \pm 1.7\end{array}$ & 0.213 & $\begin{array}{l}\leq 6.0 \% \\
6.1 \%-6.5 \% \\
6.6 \%-7.0 \% \\
7.1 \%-7.5 \% \\
7.6 \%-8.0 \% \\
>8.0 \%\end{array}$ & $\begin{array}{l}6.2 \pm 1.1 \\
6.0 \pm 1.3 \\
5.9 \pm 1.3 \\
5.6 \pm 1.6 \\
5.1 \pm 2.0 \\
5.4 \pm 1.8\end{array}$ & $<0.001$ \\
\hline
\end{tabular}


Table 4 (Continued)

\begin{tabular}{|c|c|c|c|c|c|c|}
\hline Item & $\begin{array}{l}\text { BMI }\left(\mathrm{kg} / \mathrm{m}^{2}\right) \text { categories } \\
(\mathrm{N}=1,015)\end{array}$ & Mean \pm SD $^{\#}$ & $P$-value & $\begin{array}{l}\text { HbA } A_{1 c} \text { categories } \\
(n=82 I)\end{array}$ & Mean \pm SD $^{\#}$ & $\overline{P \text {-value }}$ \\
\hline QI0: Satisfied with current blood & $<25$ & $5.7 \pm 1.3$ & $<0.001$ & $\leq 6.0 \%$ & $6.0 \pm 1.1$ & $<0.001$ \\
\hline \multirow[t]{5}{*}{ sugar levels } & $25-29.9$ & $5.1 \pm 1.6$ & & $6.1 \%-6.5 \%$ & $5.5 \pm 1.4$ & \\
\hline & $30-39.9$ & $4.8 \pm 1.8$ & & $6.6 \%-7.0 \%$ & $5.0 \pm 1.5$ & \\
\hline & $\geq 40$ & $4.7 \pm 1.9$ & & $7.1 \%-7.5 \%$ & $4.3 \pm 1.7$ & \\
\hline & & & & $7.6 \%-8.0 \%$ & $3.2 \pm 1.8$ & \\
\hline & & & & $>8.0 \%$ & $3.3 \pm 1.9$ & \\
\hline QII: I know my current blood & $<25$ & $5.8 \pm 1.5$ & 0.037 & $\leq 6.0 \%$ & $6.0 \pm 1.4$ & $<0.001$ \\
\hline \multirow[t]{5}{*}{ pressure } & $25-29.9$ & $5.6 \pm 1.5$ & & $6.1 \%-6.5 \%$ & $5.8 \pm 1.4$ & \\
\hline & $30-39.9$ & $5.3 \pm 1.7$ & & $6.6 \%-7.0 \%$ & $5.7 \pm 1.3$ & \\
\hline & $\geq 40$ & $5.4 \pm 1.6$ & & $7.1 \%-7.5 \%$ & $5.2 \pm 1.6$ & \\
\hline & & & & $7.6 \%-8.0 \%$ & $5.0 \pm 1.8$ & \\
\hline & & & & $>8.0 \%$ & $5.2 \pm 1.8$ & \\
\hline Q12: Satisfied with current blood & $<25$ & $6.1 \pm 0.9$ & 0.012 & $\leq 6.0 \%$ & $6.1 \pm 1.2$ & 0.493 \\
\hline \multirow[t]{5}{*}{ pressure } & $25-29.9$ & $6.0 \pm 1.0$ & & $6.1 \%-6.5 \%$ & $6.0 \pm 1.1$ & \\
\hline & $30-39.9$ & $5.8 \pm 1.2$ & & $6.6 \%-7.0 \%$ & $5.9 \pm 1.1$ & \\
\hline & $\geq 40$ & $5.7 \pm 1.4$ & & $7.1 \%-7.5 \%$ & $5.8 \pm 1.2$ & \\
\hline & & & & $7.6 \%-8.0 \%$ & $5.9 \pm 0.9$ & \\
\hline & & & & $>8.0 \%$ & $5.8 \pm 1.2$ & \\
\hline \multirow[t]{6}{*}{ QI3: Satisfied with current health } & $<25$ & $5.0 \pm 1.7$ & $<0.001$ & $\leq 6.0 \%$ & $4.5 \pm 1.7$ & $<0.001$ \\
\hline & $25-29.9$ & $4.7 \pm 1.7$ & & $6.1 \%-6.5 \%$ & $4.5 \pm 1.7$ & \\
\hline & $30-39.9$ & $4.0 \pm 1.6$ & & $6.6 \%-7.0 \%$ & $4.5 \pm 1.6$ & \\
\hline & $\geq 40$ & $3.5 \pm 1.7$ & & $7.1 \%-7.5 \%$ & $4.0 \pm 1.6$ & \\
\hline & & & & $7.6 \%-8.0 \%$ & $3.1 \pm 1.6$ & \\
\hline & & & & $>8.0 \%$ & $3.6 \pm 1.7$ & \\
\hline QI4: Satisfied with current level & $<25$ & $3.4 \pm 0.9$ & 0.379 & $\leq 6.0 \%$ & $3.6 \pm 0.9$ & 0.001 \\
\hline \multirow[t]{5}{*}{ of knowledge about diabetes } & $25-29.9$ & $3.5 \pm 0.9$ & & $6.1 \%-6.5 \%$ & $3.6 \pm 0.9$ & \\
\hline & $30-39.9$ & $3.4 \pm 0.9$ & & $6.6 \%-7.0 \%$ & $3.5 \pm 0.9$ & \\
\hline & $\geq 40$ & $3.4 \pm 0.9$ & & $7.1 \%-7.5 \%$ & $3.3 \pm 0.9$ & \\
\hline & & & & $7.6 \%-8.0 \%$ & $3.2 \pm 0.8$ & \\
\hline & & & & $>8.0 \%$ & $3.6 \pm 1.0$ & \\
\hline
\end{tabular}

Notes: *Higher values represent higher satisfaction or knowledge; "range: 0 , "strongly disagree" to 6, "strongly agree".

Abbreviations: CHES-Q, Current Health Satisfaction Questionnaire; BMI, body mass index; HbA ${ }_{1 \mathrm{c}}$, glycated hemoglobin; SD, standard deviation.

(on a seven-point scale) for each CHES-Q item (ie, one category change). This value allows an estimation of the amount of change in each item that would be considered important to an individual with T2DM. Additional ways to explore the meaningfulness of change and grouping of items into domains are currently being explored using clinical trial data.

\section{Discussion}

Health satisfaction is an important gauge of how various aspects of health can influence behaviors and outcomes, and low levels of health satisfaction can negatively affect patient self-care and adherence to treatment. However, the concept of health satisfaction is complex and multifactorial, and there are no other known instruments available to measure it, particularly in T2DM. The intent behind creation of the CHES-Q was to have one brief questionnaire capture all the relevant concepts of health satisfaction in T2DM (instead of multiple overlapping questionnaires), which could be readily used in clinical trials and clinical practice. The CHES-Q measures satisfaction with health concepts that may affect patients' motivation to change behaviors, including weight, energy, appetite, sleep, physical functioning, social interactions, attitude, mood, blood sugar levels, blood pressure, and current health; it also measures self-reported knowledge of current blood sugar levels, blood pressure levels, and diabetes. The CHES-Q can provide a comprehensive description of the health and well-being of individuals with T2DM. Individual item scores can be used to provide insight into specific concepts, and groups of items can be combined to create physical and emotional domain scores.

The CHES-Q was developed using a pragmatic, minimalist approach based on input from health care professionals and patients, as well as findings from the published literature and qualitative and quantitative research evaluating the attitudes of people with and without T2DM toward behaviors such as weight loss and physical activity. The current study sought to 
Table 5 CHES-Q scores by disease severity

\begin{tabular}{|c|c|c|}
\hline $\begin{array}{c}\text { Item from CHES-Q } \\
\text { Disease severity }\end{array}$ & $\mathbf{n}$ & $\begin{array}{l}\text { Mean (SD) } \\
\text { score }\end{array}$ \\
\hline \multicolumn{3}{|c|}{ QI: Satisfied with current body weight* } \\
\hline Mild & 305 & $2.97(1.802)$ \\
\hline Moderate & 602 & $2.73(1.607)$ \\
\hline Severe & 61 & $2.21(1.582)$ \\
\hline \multicolumn{3}{|c|}{ Q2: Satisfied with current level of energy* } \\
\hline Mild & 305 & $3.76(1.764)$ \\
\hline Moderate & 602 & $3.23(1.669)$ \\
\hline Severe & 61 & $2.23(1.442)$ \\
\hline \multicolumn{3}{|c|}{ Q3: Satisfied with current appetite* } \\
\hline Mild & 305 & $4.55(1.634)$ \\
\hline Moderate & 602 & $4.26(1.714)$ \\
\hline Severe & 61 & $3.11(1.827)$ \\
\hline \multicolumn{3}{|c|}{ Q4: Satisfied with ability to sleep* } \\
\hline Mild & 305 & $4.44(1.829)$ \\
\hline Moderate & 602 & $4.20(1.879)$ \\
\hline Severe & 61 & $3.10(2.07 I)$ \\
\hline \multicolumn{3}{|c|}{ Q5: Satisfied with ability to do physical activities* } \\
\hline Mild & 305 & $4.44(1.941)$ \\
\hline Moderate & 602 & $3.86(1.921)$ \\
\hline Severe & 61 & $2.44(1.803)$ \\
\hline \multicolumn{3}{|c|}{ Q6: Satisfied with ability to have social } \\
\hline \multicolumn{3}{|l|}{ interactions* } \\
\hline Mild & 305 & $5.81(1.228)$ \\
\hline Moderate & 602 & $5.55(1.452)$ \\
\hline Severe & 61 & $4.79(1.976)$ \\
\hline \multicolumn{3}{|c|}{ Q7: Satisfied with current attitudes toward } \\
\hline \multicolumn{3}{|l|}{ diabetes* } \\
\hline Mild & 305 & $5.65(1.194)$ \\
\hline Moderate & 602 & $5.24(1.439)$ \\
\hline Severe & 61 & $4.21(1.863)$ \\
\hline \multicolumn{3}{|c|}{ Q8: Satisfied with current mood* } \\
\hline Mild & 305 & $5.63(1.268)$ \\
\hline Moderate & 602 & $5.24(1.486)$ \\
\hline Severe & 61 & $4.44(2.046)$ \\
\hline \multicolumn{3}{|c|}{ Q9: I know my current blood sugar levels } \\
\hline Mild & 305 & $5.75(1.472)$ \\
\hline Moderate & 602 & $5.62(1.578)$ \\
\hline Severe & 61 & $5.31(1.979)$ \\
\hline \multicolumn{3}{|c|}{ QI0: Satisfied with current blood sugar levels* } \\
\hline Mild & 253 & $5.58(1.365)$ \\
\hline Moderate & 487 & $4.87(1.716)$ \\
\hline Severe & 47 & $3.70(1.999)$ \\
\hline \multicolumn{3}{|c|}{ QII: I know my current blood pressure* } \\
\hline Mild & 305 & $5.69(1.4 I I)$ \\
\hline Moderate & 602 & $5.42(1.588)$ \\
\hline Severe & 61 & $5.07(1.931)$ \\
\hline \multicolumn{3}{|c|}{ Q12: Satisfied with current blood pressure } \\
\hline Mild & 253 & $5.94(1.097)$ \\
\hline Moderate & 461 & $5.87(1.114)$ \\
\hline Severe & 43 & $5.72(1.221)$ \\
\hline \multicolumn{3}{|c|}{ QI3: Satisfied with current health* } \\
\hline Mild & 305 & $4.85(1.489)$ \\
\hline Moderate & 602 & $4.17(1.665)$ \\
\hline Severe & 61 & $2.75(1.650)$ \\
\hline
\end{tabular}

Table 5 (Continued)

\begin{tabular}{lll}
\hline $\begin{array}{l}\text { Item from CHES-Q } \\
\text { Disease severity }\end{array}$ & $\mathbf{n}$ & $\begin{array}{l}\text { Mean (SD) } \\
\text { score }\end{array}$ \\
\hline $\begin{array}{l}\text { Q I4: Satisfied with current level of knowledge } \\
\text { about diabetes }\end{array}$ & & \\
$\quad$ Mild & 305 & $3.39(0.893)$ \\
$\quad$ Moderate & 602 & $3.40(0.900)$ \\
$\quad$ Severe & 61 & $3.52(0.976)$ \\
\hline
\end{tabular}

Note: $* P<0.05$ for difference between groups (analysis of variance).

Abbreviations: CHES-Q, Current Health Satisfaction Questionnaire; SD, standard deviation.

confirm the content and clarity of the CHES-Q, and to assess the measurement properties of this new questionnaire.

Participants for this study were recruited through Harris Interactive and enrolled based on a self-reported diagnosis of T2DM. The majority was male, Caucasian, married, and obese or extremely obese, and had at least some college education. However, the mean BMI for subjects in the qualitative phase was lower $\left(27.9 \mathrm{~kg} / \mathrm{m}^{2}\right)$ than that of the subjects in the quantitative phase $\left(32.1 \mathrm{~kg} / \mathrm{m}^{2}\right)$. Our sample included a smaller proportion of African Americans as compared with the percentage of individuals in the USA with T2DM. Different results may have been obtained from a more diverse group of respondents. Specific to construct validity testing, only the SF-36, a general HRQoL questionnaire, was used to evaluate this property, rather than another questionnaire measuring health satisfaction. However, given that health satisfaction is a relatively new concept, no other questionnaire was available. The known-groups validity analysis was based on self-reported measures of body weight, disease severity, and $\mathrm{HbA}_{1 \mathrm{c}}$ levels. Different results may have been obtained if more objective measures were used. Future research should focus on exploring the measurement properties of the CHES-Q in a more diverse population of individuals with T2DM.

Health satisfaction, as it relates to diabetes, is a concept more specific than HRQoL because it considers satisfaction with issues relevant to people living with diabetes (eg, blood glucose and blood pressure levels, body weight), and is different from diabetes treatment satisfaction because it addresses issues not specifically related to treatment. A patient's level of satisfaction with various aspects of health may influence engagement in self-care. ${ }^{30}$ For example, if a person is satisfied with their current body weight, even if it is considered unhealthy, the person living with T2DM may not see the value in or be motivated to attempt to lose or manage their weight, ${ }^{31}$ and those with greater weight dissatisfaction are more likely to be in poorer health and engage in unhealthy 
Table 6 Minimal clinical important change estimates

\begin{tabular}{|c|c|c|c|c|c|}
\hline CHES-Q item & $\begin{array}{l}\text { Mean } \pm \text { SD baseline } \\
\text { score, all patients } \\
(\mathrm{N}=I, 0 \text { I } 5)\end{array}$ & $\begin{array}{l}\text { Mean } \pm \text { SD change } \\
\text { in stable patients } \\
(n=529)\end{array}$ & $\begin{array}{l}\text { I.0 } \\
\text { SEM }\end{array}$ & $\begin{array}{l}0.5 \\
\text { SES }\end{array}$ & $\begin{array}{l}0.5 \\
\text { RS }\end{array}$ \\
\hline QI: Satisfied with current body weight & $2.76 \pm 1.68$ & $0.08 \pm 0.97$ & 0.69 & 0.84 & 0.49 \\
\hline Q2: Satisfied with current level of energy & $3.30 \pm 1.74$ & $0.02 \pm 1.14$ & 0.83 & 0.87 & 0.57 \\
\hline Q3: Satisfied with current appetite & $4.27 \pm 1.74$ & $0.17 \pm 1.37$ & 1.01 & 0.87 & 0.69 \\
\hline Q4: Satisfied with ability to sleep & $4.20 \pm 1.91$ & $0.08 \pm 1.24$ & 0.91 & 0.96 & 0.62 \\
\hline Q5: Satisfied with ability to do physical activities & $3.92 \pm 1.98$ & $0.09 \pm 1.35$ & 0.97 & 0.99 & 0.68 \\
\hline Q6: Satisfied with ability to have social interactions & $5.57 \pm 1.46$ & $-0.03 \pm 1.10$ & 0.89 & 0.73 & 0.55 \\
\hline Q7: Satisfied with current attitudes toward diabetes & $5.30 \pm 1.44$ & $-0.17 \pm 1.05$ & 0.77 & 0.72 & 0.53 \\
\hline Q8: Satisfied with current mood & $5.30 \pm 1.50$ & $-0.07 \pm I . I I$ & 0.84 & 0.75 & 0.56 \\
\hline Q9: I know my current blood sugar levels & $5.65 \pm 1.57$ & $-0.04 \pm 1.14$ & 0.84 & 0.79 & 0.57 \\
\hline QI0: Satisfied with current blood sugar levels & $5.00 \pm 1.70 *$ & $-0.06 \pm 1.12$ & 0.84 & 0.85 & 0.56 \\
\hline QII: I know my current blood pressure & $5.46 \pm 1.58$ & $0.04 \pm 1.15$ & 0.86 & 0.79 & 0.58 \\
\hline QI2: Satisfied with current blood pressure & $5.88 \pm 1.14^{\#}$ & $0.06 \pm 0.81$ & 0.61 & 0.57 & 0.41 \\
\hline QI3: Satisfied with current health & $4.27 \pm 1.70$ & $-0.07 \pm 0.95$ & 0.70 & 0.85 & 0.48 \\
\hline Q14: Satisfied with current level of knowledge about diabetes & $3.40 \pm 0.90$ & $0.01 \pm 0.63$ & 0.46 & 0.45 & 0.32 \\
\hline
\end{tabular}

Notes: $*_{\mathrm{n}=828 ;}{ }^{*} \mathrm{n}=788$.

Abbreviations: CHES-Q, Current Health Satisfaction Questionnaire; SD, standard deviation; SEM, standard error of measurement; SES, standardized effect size; RS, responsiveness statistic.

behaviors such as being less active and yo-yo dieting. ${ }^{30} \mathrm{In}$ fact, weight gain in people with T2DM has been linked to frustration and early discontinuation or decreased adherence to treatment regimens that cause weight gain. ${ }^{32}$

The CHES-Q is the first instrument developed to specifically assess the novel concept of health satisfaction as a separate measure from well-being, functioning, or treatment satisfaction in people with T2DM. Although not developed explicitly using a conceptual model as best practice guidelines suggest, the questionnaire was developed based on input from both patients and health care providers and leveraged the vast existing knowledge in this area. The current pilot assessment of the CHES-Q instrument included a large sample size and diverse population in terms of clinical characteristics (however, the sample was limited to people in the USA who spoke English or Spanish). The CHES-Q was found to be clear and captures concepts that are meaningful and relevant to people with T2DM. All of the key measurement properties were evaluated, and when possible, a variety of approaches were used to assess them.

The CHES-Q was developed to address the identified gap in measurement of health satisfaction among people with T2DM. It was developed using a minimalist approach so that it could be incorporated as an outcome measure in Phase III clinical trials of canagliflozin. Due to time and resource constraints, full concept elicitation was not performed during instrument development, as recommended by the US Food and Drug Administration Guidance for Industry ${ }^{33}$ and by the International
Society for Pharmacoeconomics and Outcomes Research Good Research Practices Task Force when developing new patientreported outcome instruments for regulatory purposes. ${ }^{34,35}$ However, examination of data from cognitive interviews showed that participants generally endorsed the items in the CHES-Q as concepts relevant to their health satisfaction.

We acknowledge the limitations of the CHES-Q, and when possible, encourage researchers to more closely follow recommended guidance for performing concept elicitation and determining content validity. Future plans related to the CHES-Q include expanding the instrument to look at subgroups of people with T2DM (eg, those with renal impairment) based on findings from planned concept elicitation interviews. However, the methods used to develop the current version of the CHES-Q were sound and consistent with current practices of groups such as the European Organisation for Research and Treatment of Cancer, ${ }^{36-38}$ and we believe that the CHES-Q represents a step in the right direction for measuring health satisfaction. The information presented herein adds to the knowledge base on health satisfaction in T2DM, which is a key predictor of long-term clinical outcomes.

\section{Conclusion}

The CHES-Q provides a single, brief tool to evaluate satisfaction with many aspects of living with diabetes, especially as it relates to clinical outcomes such as weight, blood glucose levels, and blood pressure. As current guidelines encourage patient-centered approaches to diabetes management, the 
CHES-Q may provide valuable information about patients' perceptions about their health, which in turn, can lead to more targeted treatment and self-management plans.

\section{Acknowledgments}

The authors would like to acknowledge Richard Rubin of Johns Hopkins University School of Medicine for his input on earlier versions of this manuscript, as well as Jonathan Weiser of Harris Interactive for helping to develop the study and interpret the findings.

\section{Author contributions}

SBT developed interview guides, planned the study, wrote the draft questionnaire, and analyzed and interpreted qualitative and quantitative data. HHC and SDM interpreted qualitative and quantitative data. RDC conducted the statistical analyses, and interpreted qualitative and quantitative data. All authors contributed to the design and conduct of the research, drafting, and/or providing critical input to the manuscript, and approved the final version for submission.

\section{Disclosure}

This work was funded by Janssen Global Services. HHC and RDC are contractors of Health Outcomes Solutions and SDM is an employee of Health Outcomes Solutions, which was contracted by Janssen Global Services, LLC to conduct this research. SBT is an employee of Janssen Global Services, LLC. Editorial support was provided by Cherie Koch, of MedErgy, which was funded by Janssen Global Services, LLC. The authors report no other conflicts of interest in this work.

\section{References}

1. Shikiar R, Rentz AM. Satisfaction with medication: an overview of conceptual, methodologic, and regulatory issues. Value Health. 2004;7(2): 204-215.

2. Barbosa CD, Balp MM, Kulich K, Germain N, Rofail D. A literature review to explore the link between treatment satisfaction and adherence, compliance, and persistence. Patient Prefer Adherence. 2012;6:39-48.

3. Hanestad BR, Hornquist JO, Albrektsen G. Self-assessed quality of life and metabolic control in persons with insulin-dependent diabetes mellitus (IDDM). Scand J Soc Med. 1991;19(1):57-65.

4. Kleiman MB. Recent US trends in the age decrement in health satisfaction: preliminary findings. Int J Soc Psychiatry. 1984;30(3):213-217.

5. Pieber K, Stein KV, Herceg M, Rieder A, Fialka-Moser V, Dorner TE. Determinants of satisfaction with individual health in male and female patients with chronic low back pain. J Rehabil Med. 2012;44(8): 658-663.

6. Buchi S, Villiger B, Sensky T, Schwarz F, Wolf C, Buddeberg C. Psychosocial predictors of long-term success of in-patient pulmonary rehabilitation of patients with COPD. Eur Respir J. 1997;10(6): $1272-1277$
7. Steca P, Greco A, Monzani D, et al. How does illness severity influence depression, health satisfaction and life satisfaction in patients with cardiovascular disease? The mediating role of illness perception and self-efficacy beliefs. Psychol Health. 2013;28(7): 765-783.

8. Pan LH, Tsai YF. Quality of life in colorectal cancer patients with diarrhoea after surgery: a longitudinal study. J Clin Nurs. 2012;21(15-16):2357-2366.

9. Imayama I, Plotnikoff RC, Courneya KS, Johnson JA. Determinants of quality of life in adults with type 1 and type 2 diabetes. Health Qual Life Outcomes. 2011;9:115.

10. Dolan P, Kavetsos G, Tsuchiya A. Sick but satisfied: the impact of life and health satisfaction on choice between health scenarios. $J$ Health Econ. 2013;32(4):708-714.

11. Institute of Medicine. Crossing the quality chasm: a new health system for the 21 st century. Available from: https://www.iom.edu/ Reports/2001/Crossing-the-Quality-Chasm-A-New-Health-Systemfor-the-21st-Century.aspx. Accessed February 23, 2015.

12. Khagram L, Martin CR, Davies MJ, Speight J. Psychometric validation of the Self-Care Inventory-Revised (SCI-R) in UK adults with type 2 diabetes using data from the AT.LANTUS Follow-on study. Health Qual Life Outcomes. 2013;11:24.

13. Inzucchi SE, Bergenstal RM, Buse JB, et al. Management of hyperglycemia in type 2 diabetes: a patient-centered approach. Position statement of the American Diabetes Association (ADA) and the European Association for the Study of Diabetes (EASD). Diabetes Care. 2012;35(6): 1364-1379.

14. Rosenstock J, Aggarwal N, Polidori D, et al. Dose-ranging effects of canagliflozin, a sodium-glucose cotransporter 2 inhibitor, as add-on to metformin in subjects with type 2 diabetes. Diabetes Care. 2012;35(6): 1232-1238.

15. Baumann LC, Dang TT. Helping patients with chronic conditions overcome barriers to self-care. Nurse Pract. 2012;37(3):32-38.

16. Pun SPY, Coates VE, Benzie IFF. Barriers to the self-care of type 2 diabetes from both patients' and providers' perspectives: literature review. J Nurs Healthc Chronic Illn. 2009;1(1):4-19.

17. Harris Interactive Inc. Harris Poll Online ${ }^{\mathrm{SM}}$ panel. Harris Interactive Web site. Updated 2013. Available from: http:/www.harrisinteractive.com/ MethodsTools/DataCollection/HarrisPollOnlinePanel.aspx. Accessed February 23, 2015.

18. Ware JE. SF-36 v2 ${ }^{\circledR}$ Health Questionnaire: Administration Guide for Clinical Trial Investigators. 2008.

19. Terwee CB, Bot SD, de Boer MR, et al. Quality criteria were proposed for measurement properties of health status questionnaires. $J$ Clin Epidemiol. 2007;60(1):34-42.

20. McHorney CA, Tarlov AR. Individual-patient monitoring in clinical practice: are available health status surveys adequate? Qual Life Res. 1995;4(4):293-307.

21. Nunnally JC, Bernstein IH. Psychometric Theory. 3rd ed. New York, NY, USA: McGraw Hill; 1994.

22. Doll HA, Petersen SE, Stewart-Brown SL. Obesity and physical and emotional well-being: associations between body mass index, chronic illness, and the physical and mental components of the SF-36 questionnaire. Obes Res. 2000;8(2):160-170.

23. Williamson DA, Rejeski J, Lang W, et al. Impact of a weight management program on health-related quality of life in overweight adults with type 2 diabetes. Arch Intern Med. 2009;169(2):163-171.

24. Dixon JB, O'Brien PE. Health outcomes of severely obese type 2 diabetic subjects 1 year after laparoscopic adjustable gastric banding. Diabetes Care. 2002;25(2):358-363.

25. Adams TD, Pendleton RC, Strong MB, et al. Health outcomes of gastric bypass patients compared to nonsurgical, nonintervened severely obese. Obesity (Silver Spring). 2010;18(1):121-130.

26. Wee CC, Davis RB, Hamel MB. Comparing the SF-12 and SF-36 health status questionnaires in patients with and without obesity. Health Qual Life Outcomes. 2008;6:11. 
27. National Institutes of Health. Clinical guidelines on the identification, evaluation, and treatment of overweight and obesity in adults: the evidence report. Obes Res. 1998;6 Suppl 2:51S-209S.

28. Revicki D, Hays RD, Cella D, Sloan J. Recommended methods for determining responsiveness and minimally important differences for patient-reported outcomes. J Clin Epidemiol. 2008;61(2):102-109.

29. Guyatt GH, Osoba D, Wu AW, Wyrwich KW, Norman GR. Methods to explain the clinical significance of health status measures. Mayo Clin Proc. 2002;77(4):371-383.

30. Blake CE, Hebert JR, Lee DC, et al. Adults with greater weight satisfaction report more positive health behaviors and have better health status regardless of BMI. J Obes. 2013;2013:291371.

31. Anderson LA, Eyler AA, Galuska DA, Brown DR, Brownson RC. Relationship of satisfaction with body size and trying to lose weight in a national survey of overweight and obese women aged 40 and older, United States. Prev Med. 2002;35(4):390-396.

32. Pi-Sunyer FX. The impact of weight gain on motivation, compliance, and metabolic control in patients with type 2 diabetes mellitus. Postgrad Med. 2009;121(5):94-107.

33. US Department of Health and Human Services, Food and Drug Administration. Guidance for industry - patient-reported outcome measures: use in medical product development to support labelling claims; 2009. Updated 2009. Available from: http://www.fda.gov/downloads/Drugs/GuidanceComplianceRegulatoryInformation/Guidances/ UCM193282.pdf. Accessed February 23, 2015.
34. Patrick DL, Burke LB, Gwaltney CJ, et al. Content validity - establishing and reporting the evidence in newly developed patient-reported outcomes (PRO) instruments for medical product evaluation: ISPOR PRO Good Research Practices Task Force report: part 2 - assessing respondent understanding. Value Health. 2011;14(8):978-988.

35. Patrick DL, Burke LB, Gwaltney CJ, et al. Content validity - establishing and reporting the evidence in newly developed patient-reported outcomes (PRO) instruments for medical product evaluation: ISPOR PRO Good Research Practices Task Force Report: part 1 - eliciting concepts for a new PRO instrument. Value Health. 2011;14(8):967-977.

36. Gamper EM, Groenvold M, Petersen MA, et al. The EORTC emotional functioning computerized adaptive test: Phases I-III of a cross-cultural item bank development. Psychooncology. 2014;23(4):397-403.

37. Bottomley A, Vachalec S, Bjordal K, Blazeby J, Flechtner H, Ruyskart P. The development and utilisation of the European Organisation for research and treatment of cancer quality of life group item bank. Eur J Cancer. 2002;38(12):1611-1614.

38. Giesinger JM, Aa Petersen M, Groenvold M, et al; European Organisation for Research and Treatment of Cancer Quality of Life Group (EORTC-QLG). Cross-cultural development of an item list for computer-adaptive testing of fatigue in oncological patients. Health Qual Life Outcomes. 2011;9:19.
Patient Related Outcome Measures

\section{Publish your work in this journal}

Patient Related Outcome Measures is an international, peer-reviewed, open access journal focusing on treatment outcomes specifically relevant to patients. All aspects of patient care are addressed within the journal and practitioners from all disciplines are invited to submit their work as well as healthcare researchers and patient support groups.

\section{Dovepress}

The manuscript management system is completely online and includes a very quick and fair peer-review system. Visit http://www.dovepress. com/testimonials.php to read real quotes from published authors.

Submit your manuscript here: http://www.dovepress.com/patient-related-outcome-measures-journal 